\title{
Optimization of extraction parameters of PTP1 $\beta$ (protein tyrosine phosphatase $1 \beta$ ), inhibitory polyphenols, and anthocyanins from Zea mays L. using response surface methodology (RSM)
}

Seung Hwan Hwang ${ }^{1}$, Shin Hwa Kwon², Zhiqiang Wang ${ }^{1}$, Tae Hyun Kim ${ }^{1}$, Young-Hee Kang ${ }^{1}$, Jae-Yong Lee ${ }^{2,3}$ and Soon Sung Lim ${ }^{1,2^{*}}$

\begin{abstract}
Background: Protein tyrosine phosphatase expressed in insulin-sensitive tissues (such as liver, muscle, and adipose tissue) has a key role in the regulation of insulin signaling and pathway activation, making protein tyrosine phosphatase a promising target for the treatment of type 2 diabetes mellitus and obesity and response surface methodology (RSM) is an effective statistical technique for optimizing complex processes using a multi-variant approach.

Methods: In this study, Zea mays L. (Purple corn kernel, PCK) and its constituents were investigated for protein tyrosine phosphatase $1 \beta$ (PTP1 $\beta$ ) inhibitory activity including enzyme kinetic study and to improve total yields of anthocyanins and polyphenols, four extraction parameters, including temperature, time, solid-liquid ratio, and solvent volume, were optimized by RSM.
\end{abstract}

Results: Isolation of seven polyphenols and five anthocyanins was achieved by PTP1 $\beta$ assay. Among them, cyanidin-3-(6"malonylglucoside) and 3'-methoxyhirsutrin showed the highest PTP1 $\beta$ inhibition with $I_{50}$ values of 54.06 and $64.04 \mu \mathrm{M}$, respectively and $4.52 \mathrm{mg}$ gallic acid equivalent/g (GAE/g) of total polyphenol content (TPC) and $43.02 \mathrm{mg}$ cyanidin-3-glucoside equivalent/100 g (C3GE/100g) of total anthocyanin content (TAC) were extracted at $40^{\circ} \mathrm{C}$ for $8 \mathrm{~h}$ with a $33 \%$ solid-liquid ratio and a 1:15 solvent volume. Yields were similar to predictions of $4.58 \mathrm{mg}$ GAE/g of TPC and $42.28 \mathrm{mg}$ C3GE/100 $\mathrm{g}$ of TAC.

Conclusion: These results indicated that PCK and 3'-methoxyhirsutrin and cyanidin-3-(6"malonylglucoside) might be active natural compounds and could be apply by optimizing of extraction process using response surface methodology.

Keywords: Zea mays L., Protein tyrosine phosphatase 1 $\beta$, Response surface methodology, Anthocyanin, Polyphenol

Abbreviations: ATC, Anthocyanin; CCD, Central composite design; EY, Extract yield; HSCCC, High speed counter current chromatography; IR, Insulin receptors; IRS, Insulin receptor substrate; PC, Purple corn; PCK, Purple corn kernel; pNPP, N p-nitrophenyl phosphate; PTP1 $\beta$, Protein tyrosine phosphatase; $1 \beta$ RSM, Response surface methodology; SHP2, SH2-domain-containing phosphotyrosine phosphatase; TAC, Total anthocyanin content; T2DM, Type 2 diabetes mellitus; TPC, Total polyphenol content

\footnotetext{
*Correspondence: limss@hallym.ac.kr

1 Department of Food Science and Nutrition, Hallym University, 1

Hallymdeahak-gil, Chuncheon 24252, Republic of Korea

'Department of Natural Medicine, Hallym University, 1 Hallymdeahak-gil,

Chuncheon 24252, Republic of Korea

Full list of author information is available at the end of the article
} 


\section{Background}

Zea mays L. (Purple corn, PC) has a variety of kernel colors, such as white, yellow, red, purple, brown, green, and blue. PC has been cultivated in Latin America, mainly in Peru, and Peruvian people have been utilizing PC for centuries. Anthocyanin (ATC), a source of color in PC, is approved in Japan as an extract, and is listed in the "Existing Food Additive List" as PC color. ATC reportedly has various biological activities, such as antioxidant [1], anti-mutagenic [2], and anti-cancer activities [3]. Numerous studies have identified and characterized the possible bioactivities of phenolic compounds from PC. Previous phytochemical investigations of PC studied cyanidin-3-glucoside, pelargonidin-3-glucoside, and peonidin-3-glu-coside by HPLC-MS [4]. Prior work by Pascual-Teresa et al. also identified cyanidin-3-(6malon-glucoside), pelargonidin-3-(6-malon-glucoside) and peonidin-3-(6-malon-glucoside) [5]. Recently, phenolic constituents were isolated from a $35 \%$ ethanol extract of purple corn kernel (PCK). Among the isolated compounds, hirstrin, 3'-methoxyhirstrin, cyanidin-3-(6"malonylglucoside), ferulic acid, $p$-hydroxycinnamic acid, and 2,4,6-trihydroxybenzoic acid, exhibited strong inhibitory effects on aldose reductase and galactitol accumulation in rat lenses and erythrocytes, and on mesangial fibrosis and inflammation, with the added effects of slowed diabetes-associated glomerulosclerosis and displayed anti-diabetic [6-8].

Protein tyrosine phosphatase (PTP) expressed in insulin-sensitive tissues (such as liver, muscle, and adipose tissue) has a key role in the regulation of insulin signaling and pathway activation [9], making PTP a promising target for the treatment of type 2 diabetes mellitus (T2DM) and obesity [10]. Although several PTPs, such as PTP- $\alpha$, leukocyte antigen-related tyrosine phosphatase (LAR), and $\mathrm{SH} 2$-domain-containing phosphotyrosine phosphatase (SHP2), have been implicated in the regulation of insulin signaling, there is substantial evidence supporting PTP1 $\beta$ as the critical PTP controlling the insulin signaling pathway. PTP1 $\beta$ can interact with and dephosphorylate activated insulin receptors (IR), as well as insulin receptor substrate (IRS) proteins [11]. For this reason, researchers are focused on finding safe, potent, non-toxic PTP1 $\beta$ inhibitors from natural and synthetic sources. Polyphenols isolated from the fruit of Phellinus linteus and Prunella vulgaris $\mathrm{L}$. are reported to inhibit PTP1 $\beta$ and confer antidiabetic effects [12].

Response surface methodology (RSM) is an effective statistical technique for optimizing complex processes using a multi-variant approach [13]. Before applying the RSM, it is necessary to choose an experimental design that defines which experiments should be performed in a given study. The main advantage of this technology is that fewer experimental trials are needed to evaluate multiple factors and their interactions, making it less laborious and time-consuming than other optimization techniques (e.g., the "one-variable-at-a-time" optimization). RSM has been successfully used for extract optimization of phenolic compounds and antioxidant of grape peel [14]. Recently, Pedro et al. optimized the total flavonoid, polyphenol, and anthocyanins of black rice using RSM coupled with central composite design (CCD), allowing rapid screening of a wide range of conditions while also indicating the role of each factor [15].

To date, no data have been published on the inhibitory effects of PCK extracts on PTP $1 \beta$ regulation. Therefore, the inhibitory effects of compounds isolated from PCK on PTP1 $\beta$ activity were investigated to evaluate potential treatments of diabetic complications. Optimization of various conditions, such as extraction temperature, extraction time, solid-liquid ratio, and solvent volume, for were studied to assess potential development of PTP1 $\beta$ inhibitors and to maximize the extract yield (EY), total polyphenol content (TPC), and total anthocyanin content (TAC) from PCK using by RSM.

\section{Methods}

\section{Plant materials and reagents}

Commercially grown PCK was obtained from Gangwon-do agricultural research and extension services in Korea (April, 2014). The plants were identified by Emeritus Professor H.J. Chi at Seoul National University, and voucher specimens were deposited in the Center for Efficacy Assessment and Development of Functional Foods and Drugs, Hallym University in with voucher number RIC-2014-NP-0415. Fresh PCK was dried at $45^{\circ} \mathrm{C}$ in a drying oven and then stored at room temperature. A PTP1 $\beta$ (human, recombinant) drug discovery kit was purchased from BIOMOL $^{\bullet}$ International LP (Plymouth meeting, PA). Sodium chloride, $p$-nitrophenyl phosphate $(p N P P)$, and dithiothreitol were obtained from SigmaAldrich Co. (St. Louis, MO, USA) for use as synthetic substrates. All other chemicals and reagents used were of analytical grade.

\section{Extraction, fractionation and isolation}

Dried PCK $(1.0 \mathrm{~kg})$ was ground and extracted with $35 \%$ ethanol for $8 \mathrm{~h}$ at room temperature. The total filtrate was concentrated to dryness in vacuo at $40{ }^{\circ} \mathrm{C}$. The PCK $35 \%$ ethanol extract powder (500 g) was applied to an open glass column packed with Diaion HP-20 and eluted with water to wash any sugars or impure components. The packing was then suspended in water and partitioned sequentially with $n$-Hexane, $\mathrm{CH}_{2} \mathrm{Cl}_{2}$, EtOAc, and $n-\mathrm{BuOH}$, leaving a residual aqueous fraction. The EtOAc fraction showed inhibitory activity on PTP $1 \beta$, hence $5.5 \mathrm{~g}$ of extract was subjected to C18 gel column chromatography eluted with water and increasing methanol in an 
Table 1 Inhibitory effect of the crude extract and fractions of Zea mays L. on protein tyrosine phosphatase $1 \beta$

\begin{tabular}{llll}
\hline Extract and fractions & $\begin{array}{l}\text { Concentration } \\
(\mu \mathrm{g} / \mathrm{mL})\end{array}$ & Inhibition $(\%)$ & $\mathrm{IC}_{50}{ }^{\mathrm{b}}(\mu \mathrm{g} / \mathrm{mL})$ \\
\hline Suramin $^{\mathrm{a}}$ & 12.97 & 61.88 & \\
& 6.49 & 40.62 & 7.51 \\
& 3.21 & 10.69 & \\
EtOH ext. & 100 & 43.99 & - \\
$n-\mathrm{Hex}$ fr. & 100 & 25.54 & - \\
$\mathrm{CH}_{2} \mathrm{Cl}_{2}$ fr. & 100 & 28.12 & - \\
EtOAc fr. & 100 & 83.88 & \\
& 50 & 57.23 & 26.12 \\
& 10 & 44.77 & \\
$n-\mathrm{BuOH}$ fr. & 100 & 70.89 & \\
& 50 & 45.09 & 58.20 \\
& 10 & 26.87 & - \\
Water fr. & 100 & 47.50 & -
\end{tabular}

${ }^{a}$ Suramin was used as positive control

${ }^{\mathrm{b}}$ The $\mathrm{IC}_{50}$ value was defined as the half-maximal inhibitory concentration and mean of 3 duplicate analyses of each sample

$\mathrm{H}_{2} \mathrm{O}-\mathrm{MeOH}$ gradient system $(95: 5 \rightarrow 0: 50, \mathrm{v} / \mathrm{v})$ to obtain 7 compounds. Also, the $n-\mathrm{BuOH}$ fraction ( $1.0 \mathrm{~g}$ ) was subjected to high speed counter current chromatography (HSCCC). The HSCCC system employed in the present study was a Model TBE-1000A HSCCC (Shanghai Tauto Bio technique, Shanghai, China) with 3 multilayer coil columns connected in series and was equipped with a $50-\mathrm{mL}$ sample loop. The inner diameter of the PTFE tubing was $1.8 \mathrm{~mm}$, and the total volume capacity was $1000 \mathrm{~mL}$. The b-value of the preparative column varied from 0.42 at the internal layer to 0.63 at the external layer. The rotation speed of the apparatus was regulated using a speed controller in the range of 0-600 rpm. The HSCCC system was equipped with a Model Hitachi L-6200 intelligent pump (Hitachi, Tokyo, Japan), Model TOPAZ dual UV monitor operating at $520 \mathrm{~nm}$, and Model ECOMAC-ECOM Acquisition and Control (version 0.97). The upper phase, consisting of a mixture of $n-\mathrm{BuOH}$ :acetic acid:water $(4: 1: 5, \mathrm{v} / \mathrm{v} / \mathrm{v})$ was used as the stationary phase, while the lower phase was used as the mobile phase. The mobile phase was pumped at $2.5 \mathrm{~mL} / \mathrm{min}$, while centrifugation was carried out at $400 \mathrm{rpm}$. As a result, 12 compounds were isolated and identified by ${ }^{1} \mathrm{H} \&{ }^{13} \mathrm{C}$ NMR spectra (COSY, HMBC, HMQC and DEPT) and LC-MS/MS.

\section{Assay method of PTP1 $\beta$ inhibitory activity}

A PTP1 $\beta$ (human, recombinant) drug discovery kit was purchased from BIOMOL $^{\bullet}$ International LP (Plymouth meeting, PA). Enzymatic activity was measured using $p$ NPP, as described previously. To each of the 96-wells in a microtiter plate (final volume: $100 \mu \mathrm{L}$ ) was added 2 $\mathrm{mM} p \mathrm{NPP}$ and PTP1 $\beta$ (0.05-0.1 ng/well) in a buffer containing $50 \mathrm{mM}$ citrate ( $\mathrm{pH} 6.0), 0.1 \mathrm{M}$ sodium chloride, $1 \mathrm{mM}$ EDTA, and $1 \mathrm{mM}$ dithiothreitol, with or without test compounds. Following incubation at $37{ }^{\circ} \mathrm{C}$ for $30 \mathrm{~min}$, the reaction was terminated with $10 \mathrm{M}$ sodium<smiles>[R1]c1c([18F])c(O)cc(Br)c1C(=O)O</smiles>

1: $\mathrm{R}_{1}=\mathrm{OH}, \mathrm{R}_{2}=\mathrm{H}, \mathrm{R}_{3}=\mathrm{H}$; Protocatechuic acid 2: $\mathrm{R}_{1}=\mathrm{OCH}_{3}, \mathrm{R}_{2}=\mathrm{H}, \mathrm{R}_{3}=\mathrm{H}$; Vanillic acid $3: \mathrm{R}_{1}=\mathrm{H}, \mathrm{R}_{2}=\mathrm{OH}, \mathrm{R}_{3}=\mathrm{OH} ; 2,4,6$-Trihydroxy benzoic acid<smiles>O=c1c(O[C@@H]2O[C@H](CO)[C@@H](O)[C@H](O)[C@H]2O)c(-c2ccc(O)c(Br)c2)oc2cc(O)cc(O)c12</smiles>

6: $\mathrm{R}_{1}=\mathrm{OH} ;$ Hirsutrin

7: $\mathrm{R}_{1}=\mathrm{OCH}_{3} ; 3^{\prime}-$ Methoxyhirsutrin<smiles>O=C(O)/C=C/c1ccc(O)c(Br)c1</smiles>

$4: \mathrm{R}_{1}=\mathrm{H} ; p$-Hydroxycinnamic acid $5: \mathrm{R}_{1}=\mathrm{OCH}_{3} ;$ Ferulic acid<smiles></smiles>

8: $\mathrm{R}_{1}=\mathrm{OH}, \mathrm{R}_{2}=\mathrm{H}$; Cyanidin-3-glucoside 9: $\mathrm{R}_{1}=\mathrm{H}, \mathrm{R}_{2}=\mathrm{H}$; Pelargonidin-3-glucoside $10 \mathrm{R}_{1}=\mathrm{OCH}_{3}, \mathrm{R}_{2}=\mathrm{H}$; Peonidin-3-glucoside

11: $\mathrm{R}_{1}=\mathrm{OH}, \mathrm{R}_{2}=$ Malonyl; Cyanidin 3-(6"-malonylglucoside)

12: $\mathrm{R}_{1}=\mathrm{H}, \mathrm{R}_{2}=$ Malonyl; Pelargonidin 3-(6"-malonylglucoside)

Fig. 1 Chemical structures of compounds $1-12$ isolated from Zea mays L 
Table 2 Inhibitory effect of the isolated compounds from Zea mays $L$. on protein tyrosine phosphatase $1 \beta$

\begin{tabular}{|c|c|c|c|c|}
\hline Compounds & $\begin{array}{l}\text { Concentration } \\
(\mu \mathrm{g} / \mathrm{mL})\end{array}$ & $\begin{array}{l}\text { Inhibition } \\
(\%)\end{array}$ & $\begin{array}{l}I_{50}{ }^{b} \\
(\mu \mathrm{g} / \mathrm{ml})\end{array}$ & $I_{50}(\mu \mathrm{M})$ \\
\hline \multirow[t]{3}{*}{ Suramin ${ }^{a}$} & 5 & 64.32 & & \multirow[t]{3}{*}{2.76} \\
\hline & 2.5 & 46.46 & 3.94 & \\
\hline & 1 & 10.69 & & \\
\hline Protochtechuic acid (1) & 100 & $<50.0$ & - & - \\
\hline Vanillic acid (2) & 100 & $<50.0$ & - & - \\
\hline $\begin{array}{l}\text { 2,4,6-Trihydroxybenzoic } \\
\text { acid (3) }\end{array}$ & 100 & $<50.0$ & - & - \\
\hline $\begin{array}{l}p \text {-Hydroxycinnamic } \\
\text { acid (4) }\end{array}$ & 100 & $<50.0$ & - & - \\
\hline \multirow[t]{3}{*}{ Ferulic acid (5) } & 100 & 96.09 & & \multirow[t]{3}{*}{185.41} \\
\hline & 50 & 64.53 & 35.97 & \\
\hline & 10 & 28.33 & & \\
\hline Hirsutrin (6) & 100 & $<50.0$ & - & - \\
\hline \multirow[t]{3}{*}{ 3'-Methoxyhirsutrin (7) } & 50 & 85.89 & & \multirow[t]{3}{*}{64.04} \\
\hline & 25 & 36.84 & 30.61 & \\
\hline & 10 & 15.02 & & \\
\hline Cyanidin-3-glucoside (8) & 100 & $<50.0$ & - & - \\
\hline \multirow{3}{*}{$\begin{array}{l}\text { Pelargonidin-3- } \\
\text { glucoside (9) }\end{array}$} & 100 & 55.05 & & \multirow[t]{3}{*}{210.81} \\
\hline & 50 & 13.35 & 91.36 & \\
\hline & 10 & 1.09 & & \\
\hline Peonidin-3-glucoside (10) & 100 & $<50.0$ & - & - \\
\hline \multirow{3}{*}{$\begin{array}{l}\text { Cyanidin-3-(6"- } \\
\text { malonylglucoside) (11) }\end{array}$} & 50 & 91.73 & & \multirow[t]{3}{*}{54.06} \\
\hline & 25 & 36.24 & 28.95 & \\
\hline & 10 & 18.54 & & \\
\hline $\begin{array}{l}\text { Peonidin-3-(6"- } \\
\text { malonylglucoside) (12) }\end{array}$ & 100 & $<50.0$ & - & - \\
\hline
\end{tabular}

${ }^{a}$ Suramin was used as positive control

${ }^{\mathrm{b}}$ The $\mathrm{IC}_{50}$ value was defined as the half-maximal inhibitory concentration and mean of 3 duplication analyses of each sample hydroxide. The amount of $p$-nitrophenol produced was estimated by measuring the absorbance at $405 \mathrm{~nm}$. The non-enzymatic hydrolysis of $2 \mathrm{mM} p \mathrm{NPP}$ was corrected by measuring the increase in absorbance at $405 \mathrm{~nm}$ obtained in the absence of PTP1 $\beta$ enzyme.

\section{Kinetics of PTP1 $\beta$ by active compounds}

Inhibition kinetics studies were carried out in the absence and presence of active compounds with various concentrations of $p \mathrm{NPP}(0.1,0.5$ and $1.0 \mathrm{mM})$ as substrate. The initial rate was determined on the basis of the rate of increase in absorbance at $405 \mathrm{~nm}$. The Michaelis-Menten constant $\left(K_{m}\right)$ and maximal velocity $\left(V_{\max }\right)$ of PTP1 $\beta$ were determined by Lineweaver-Burk Plot analysis for competitive inhibition, and the intercept on the vertical axis for noncompetitive inhibition [16].

\section{Extraction process}

The dried PCK $(1.0 \mathrm{~g})$ was accurately weighed and placed in a capped tube and mixed with $10 \mathrm{~mL}$ of $35 \%$ ethanol. After wetting the plant material, the tube containing the suspension was immersed at $37{ }^{\circ} \mathrm{C}$ in a water bath and irradiated for the predetermined for $30 \mathrm{~min}$. After extraction, the sample was centrifuged at 3000 rpm for $3 \mathrm{~min}$. The supernatant was collected and diluted with eluent. All samples were filtered through $0.45 \mu \mathrm{m}$ syringe filter.

\section{Experimental design for RSM}

The effects of the four independent processing parameters (extraction temperature $\left(\mathrm{X}_{1},{ }^{\circ} \mathrm{C}\right)$, extraction time $\left(\mathrm{X}_{2}\right.$, hour), solid-liquid ratio $\left(\mathrm{X}_{3}, \%\right)$, and solvent volume $\left.\left(\mathrm{X}_{4}, 1: \mathrm{X}\right)\right)$, on the dependent variables were investigated using RSM. The CCD for RSM required only five levels, coded as $-2,-1,0,+1,+2$. The total number of experiments designed was 27 based on the five levels and a four-factor experimental design, with five replicates at the central conditions of the design for estimation of a pure error sum of squares. The dependent variables were

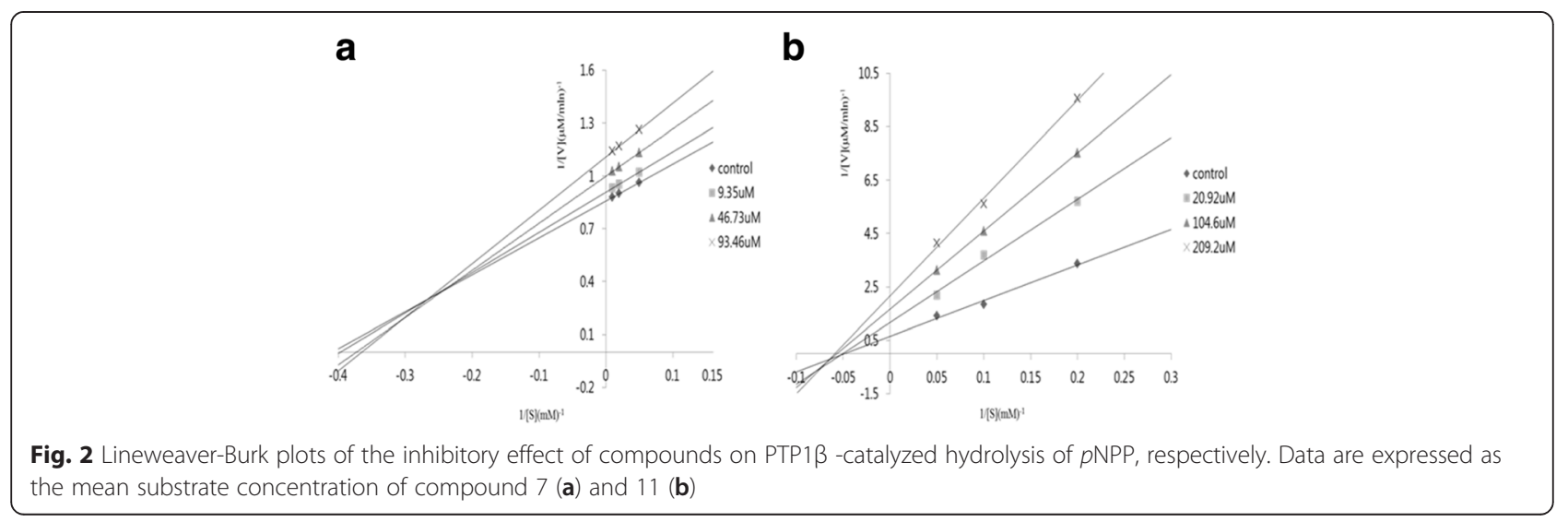


Table 3 Experimental range and values of the independent variables in the central composite design for optimization of extraction conditions

\begin{tabular}{|c|c|c|c|c|c|c|c|}
\hline \multirow[t]{2}{*}{ No. } & \multicolumn{4}{|c|}{ Independent } & \multicolumn{3}{|c|}{ Response variables } \\
\hline & $\mathrm{X}_{1}^{\mathrm{a}}$ & $x_{2}$ & $x_{3}$ & $X_{4}$ & $\overline{Y_{1}^{b}}$ & $Y_{2}$ & $Y_{3}$ \\
\hline 1 & $30(-1)$ & $6(-1)$ & $25(-1)$ & $12(-1)$ & 5.91 & 55.16 & 6.00 \\
\hline 2 & $50(1)$ & $6(-1)$ & $25(-1)$ & $12(-1)$ & 3.40 & 32.06 & 7.65 \\
\hline 3 & $30(-1)$ & $10(1)$ & $25(-1)$ & $12(-1)$ & 6.55 & 65.20 & 6.00 \\
\hline 4 & $50(1)$ & $10(1)$ & $25(-1)$ & $12(-1)$ & 5.47 & 47.47 & 6.70 \\
\hline 5 & $30(-1)$ & $6(-1)$ & $35(1)$ & $12(-1)$ & 6.32 & 66.17 & 5.85 \\
\hline 6 & $50(1)$ & $6(-1)$ & $35(1)$ & $12(-1)$ & 2.04 & 16.61 & 8.50 \\
\hline 7 & $30(-1)$ & $10(1)$ & $35(1)$ & $12(-1)$ & 8.08 & 77.94 & 6.15 \\
\hline 8 & $50(1)$ & $10(1)$ & $35(1)$ & $12(-1)$ & 3.70 & 34.71 & 7.30 \\
\hline 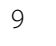 & $30(-1)$ & $6(-1)$ & $25(-1)$ & $12(-1)$ & 4.42 & 41.02 & 6.30 \\
\hline 10 & $50(1)$ & $6(-1)$ & $25(-1)$ & $20(1)$ & 6.64 & 67.21 & 7.75 \\
\hline 11 & $30(-1)$ & $10(1)$ & $25(-1)$ & $20(1)$ & 6.33 & 63.36 & 6.25 \\
\hline 12 & $50(1)$ & $10(1)$ & $25(-1)$ & $20(1)$ & 6.47 & 65.81 & 7.10 \\
\hline 13 & $30(-1)$ & $6(-1)$ & $35(1)$ & $20(1)$ & 5.75 & 58.94 & 6.35 \\
\hline 14 & $50(1)$ & $6(-1)$ & $35(1)$ & $20(1)$ & 3.62 & 70.81 & 9.25 \\
\hline 15 & $30(-1)$ & $10(1)$ & $35(1)$ & $20(1)$ & 6.30 & 64.96 & 6.35 \\
\hline 16 & $50(1)$ & $10(1)$ & $35(1)$ & $20(1)$ & 4.67 & 69.92 & 9.00 \\
\hline 17 & $20(-2)$ & $8(0)$ & $30(0)$ & $16(0)$ & 3.41 & 20.63 & 5.75 \\
\hline 18 & $60(2)$ & $8(0)$ & $30(0)$ & $16(0)$ & 3.80 & 24.07 & 9.10 \\
\hline 19 & $40(0)$ & $4(-2)$ & $30(0)$ & $16(0)$ & 4.64 & 40.02 & 5.95 \\
\hline 20 & $40(0)$ & $12(2)$ & $30(0)$ & $16(0)$ & 4.63 & 37.48 & 6.00 \\
\hline 21 & $40(0)$ & $8(0)$ & $20(-2)$ & $16(0)$ & 6.22 & 52.90 & 6.40 \\
\hline 22 & $40(0)$ & $8(0)$ & $40(2)$ & $16(0)$ & 4.92 & 71.46 & 5.75 \\
\hline 23 & $40(0)$ & $8(0)$ & $30(0)$ & $8(-2)$ & 6.63 & 60.04 & 2.70 \\
\hline 24 & $40(0)$ & $8(0)$ & $30(0)$ & $24(+2)$ & 5.72 & 56.32 & 6.35 \\
\hline 25 & $40(0)$ & $8(0)$ & $30(0)$ & $16(0)$ & 4.95 & 45.34 & 5.75 \\
\hline 26 & $40(0)$ & $8(0)$ & $30(0)$ & $16(0)$ & 4.34 & 35.13 & 5.78 \\
\hline 27 & $40(0)$ & $8(0)$ & $30(0)$ & $16(0)$ & 4.28 & 40.88 & 5.73 \\
\hline
\end{tabular}

${ }^{a} \mathrm{X}_{1}$, extraction temperature $\left({ }^{\circ} \mathrm{C}\right) ; \mathrm{X}_{2}$, extraction time (hour); $\mathrm{X}_{3}$, solid-liquid ratio (\%); $\mathrm{X}_{4}$, solvent volume $(1: \mathrm{X})$

${ }^{b} Y_{1}$, total polyphenol content (mg GAE/g); $Y_{2}$, total anthocyanin content (mg C3GE/100 g) $\mathrm{Y}_{3}$, extraction yield (\%)
TPC $\left(\mathrm{Y}_{1}\right)$, TAC $\left(\mathrm{Y}_{2}\right)$, and EY $\left(\mathrm{Y}_{3}\right)$. The model equation for the response $(\mathrm{Y})$ to the three independent variables $\left(\mathrm{X}_{1}, \mathrm{X}_{2}, \mathrm{X}_{3}\right.$ and $\left.\mathrm{X}_{4}\right)$ is given in the following equation:

$$
\boldsymbol{Y}=\boldsymbol{\beta}_{0}+\sum_{i=1}^{2} \boldsymbol{\beta}_{i} \boldsymbol{X}_{\boldsymbol{i}}+\sum_{i=1}^{2} \boldsymbol{\beta}_{i i} \boldsymbol{X}_{\boldsymbol{i}}^{2}+\sum_{\boldsymbol{i}} \sum_{j=i+1} \boldsymbol{\beta}_{i j} \boldsymbol{X}_{\boldsymbol{i}} \mathbf{X}_{\mathbf{j}}
$$

\section{Total polyphenol content determination}

Total polyphenol content (TPC) was determined according to the Folin Denis Method with a slight modification. The extract was double-diluted and $100 \mu \mathrm{L}$ of the diluted sample was mixed with $50 \mu \mathrm{L}$ Folin Ciocalteu' reagent and $300 \mu \mathrm{L}$ of $2 \%(\mathrm{w} / \mathrm{v})$ sodium carbonate. After incubating the samples at room temperature for $1 \mathrm{~h}, 1 \mathrm{~mL}$ water was added before measuring the absorbance at $750 \mathrm{~nm}$. The calibration curve was obtained using gallic acid in the same manner as done for the sample $\left(R^{2}=0.999\right)$. Results were expressed as mg of gallic acid equivalent (GAE) per $\mathrm{g}$ of dried weight.

\section{Total anthocyanin content determination}

Total anthocyanin (TAC) was used to indicate the contents of anthocyanin extracted from PCK. TAC was determined using a $\mathrm{pH}$ differential method. Absorbencies were read at 530 and $700 \mathrm{~nm}$. Pigment content was calculated as cyanidin-3-glucoside (C3G) using an extinction coefficient $(\varepsilon)$ of 26,900 and a molecular weight of 449.2 and expressed as mg cyanidin-3-glucoside equivalent (C3GE) per $100 \mathrm{~g}$ of dried weight [17].

\section{Determination of extraction yield}

The PCK extracts were concentrated in an efficient centrifugal concentration system (EZ-2 plus, Genevac and $\mathrm{UK}$ ) and the difference in weight corresponds to the soluble solid (total extract yield) of the dried PCK.

\section{Data analysis}

All calculations and analyses were performed using statistical analysis system (SAS, SAS Institude Inc., NC, USA, version 9.1) software and Sigma plot (Systat

Table 4 Polynomial equations calculated using the RSM program for extraction conditions of Zea mays L.

\begin{tabular}{llll}
\hline Response variables & Second order polynomial equations ${ }^{a}$ & $R^{2}$ & $p$-value \\
\hline Total polyphenol content & $Y_{\text {TPC }}=12.967917+0.236917 X_{1}+0.119583 X_{2}-0.184667 X_{3}-1.221042 X_{4}-0.001699 X_{12}-0.000781 X_{1} X_{2}+$ & 0.935 & 0.0001 \\
(mg GAE/g) & $0.021901 X_{2}^{2}-0.013988 X_{1} X_{3}+0.003563$ & \\
& $X_{2} X_{3}+0.012854 X_{3}^{2}+0.16953 X_{1} X_{4}^{2}-0.021797 X_{2} X_{4}-0.007281 X_{3} X_{4}+0.029538 X_{4}^{2}$ & \\
Total anthocyanin content & $Y_{T A C}=412.389167+0.248000 X_{1}+4.349167 X_{2}-14.648667 X_{3}-23.737500 X_{4}-0.027356 X_{12}-0.058562 X_{1} X_{2}+$ & 0.917 & 0.0001 \\
(mg C3GE/100 g) & $0.341094 X_{2}^{2}-0.079975 X_{1} X_{3}-0.072875 X_{2} X_{3}+0.288875 X_{3}^{2}+0.279406 X_{1} X_{4}^{2}-0.230156 X_{2} X_{4}+$ & \\
& $0.099687 X_{3} X_{4}+0.388867 X_{4}^{2}$ & 0.887 & 0.0001 \\
Extraction yield (\%) & $Y_{E Y}=29.279167-0.538500 X_{1}-0.842500 X_{2}-0.823000 X_{3}-0.010833 X_{4}+0.006002 X_{12}-0.007188 X_{1} X_{2}+$ & \\
& $0.059427 X_{2}^{2}+0.004625 X_{1} X_{3}-0.003125 X_{2} X_{3}+0.010508 X_{3}^{2}+0.004219 X_{1} X_{4}^{2}+0.014844 X_{2} X_{4}+$ & \\
& $0.003437 X_{3} X_{4}-0.0077997 X_{4}^{2}$ & & \\
\hline
\end{tabular}

${ }^{a} X_{1}$, extraction temperature $\left({ }^{\circ} \mathrm{C}\right) ; \mathrm{X}_{2}$, extraction time (hour); $\mathrm{X}_{3}$, solid-liquid ratio $(\%) ; \mathrm{X}_{4}$, solvent volume $(1: \mathrm{X})$ 
Table 5 Predicted levels of extraction condition for the maximum response of extraction conditions by the ridge analysis in Zea mays L.

\begin{tabular}{|c|c|c|c|c|c|c|}
\hline \multirow[t]{2}{*}{ Response variables } & \multicolumn{4}{|c|}{ Optimum extraction conditions ${ }^{\mathrm{a}}$} & \multirow[t]{2}{*}{ Maximum } & \multirow[t]{2}{*}{ Morphology } \\
\hline & $X_{1}$ & $x_{2}$ & $x_{3}$ & $X_{4}$ & & \\
\hline Total polyphenol content (mg GAE/g) & 29.02 & 8.99 & 33.67 & 10.25 & 7.89 & Saddle point \\
\hline Total anthocyanin content (mg C3GE/100 g) & 45.22 & 7.85 & 34.14 & 22.97 & 82.44 & Saddle point \\
\hline Extraction yield (\%) & 58.87 & 7.53 & 32.31 & 17.65 & 10.33 & Saddle point \\
\hline
\end{tabular}

${ }^{a} X_{1}$, extraction temperature $\left({ }^{\circ} \mathrm{C}\right) ; \mathrm{X}_{2}$, extraction time (hour); $\mathrm{X}_{3}$, solid-liquid ratio $(\%) ; \mathrm{X}_{4}$, solvent volume $(1: \mathrm{X})$

Software Inc., USA, version 11). Inhibition rates were calculated as percentages (\%) with respect to the control value and $\mathrm{IC}_{50}$ value was estimated from the leastsquares regression line of the logarithmic concentration plotted against inhibitory activity.

\section{Result}

\section{PTP1 $\beta$ inhibitory compounds from Zea mays L}

The present study was carried out to obtain new potential PTP1 $\beta$ inhibitors from PCK. In order to identify the active compounds from PCK, its extract was systematically divided into 5 fractions, which were then tested for PTP $1 \beta$ inhibitory activity. Among them, the EtOAc fraction was found to have moderate PTP $1 \beta$ inhibitory activity with a mean $\mathrm{IC}_{50}$ value of $26.12 \mu \mathrm{g} / \mathrm{mL}$, whereas the positive control suramin showed an $\mathrm{IC}_{50}$ value of $7.51 \mu \mathrm{g} / \mathrm{mL}$ (Table 1). This suggested the presence of PTP1 $\beta$ inhibition in the EtOAc fraction.

\section{Isolation of the compounds from active EtOAc fraction}

The active EtOAc fraction $\left(\mathrm{IC}_{50}=26.12 \mu \mathrm{g} / \mathrm{mL}\right)$ was subjected to repeated chromatography on a reversed phase $\mathrm{C}-18$ gel chromatography column, yielding protocatechuic acid (1) (5.1 mg), vanillic acid (2) (12.6 mg), 2,4,6-trihydroxy benzoic acid (3) (6.5 mg), p-4-hydroxycinnamic acid (4) (15.0 mg), ferulic acid (5) (5.5 mg), hirsutrin (6) (21.0 mg), and 3'-methoxyhirsutrin (7) $(20.0 \mathrm{mg})$. Also, the $n-\mathrm{BuOH}$ fraction $\left(\mathrm{IC}_{50}=58.20 \mu \mathrm{g} / \mathrm{mL}\right)$ was subjected to HSCCC, yielding cyanidin-3-glucoside (8) (6.8 $\mathrm{mg})$, pelargonidin-3-glucoside (9) $(1.7 \mathrm{mg})$, peonidin3-glucoside (10) (1.7 mg), cyanidin-3-(6"-malonylglucoside) (11) $(7.6 \mathrm{mg})$, and pelargonidin-3-(6"-malonylglucoside) (12) (5.4 mg) in Fig. 1. The inhibitory activities of compounds 1-12 were assayed against PTP1 $\beta$, and the results are presented in Table 2. The known PTP1 $\beta$ inhibitor, suramin $\left(\mathrm{IC}_{50}=2.76 \mu \mathrm{M}\right)$, was used as a positive control. Among the extracts, compounds 5, 7, 9 and 11 exhibited moderate activity with $\mathrm{IC}_{50}$ values of $185.41,64.04,210.81$, and $54.06 \mu \mathrm{M}$, respectively. This suggests that addition of a methyl group to the phenolic acid skeleton may be responsible for a loss of in vitro activity. Addition of malonylglucoside to the cyanidin skeleton may also be responsible for loss of in vitro activity. In a previous study of anti-diabetic compounds from PCK extract, it was demonstrated that the anthocyanins isolated from PCK could inhibit renal fibrosis for mesangial inflammation specific therapies in a high-glucose-induced diabetic nephropathy model [7]. Moreover, compounds 6, 7, and 11 from PCK showed significant inhibitory
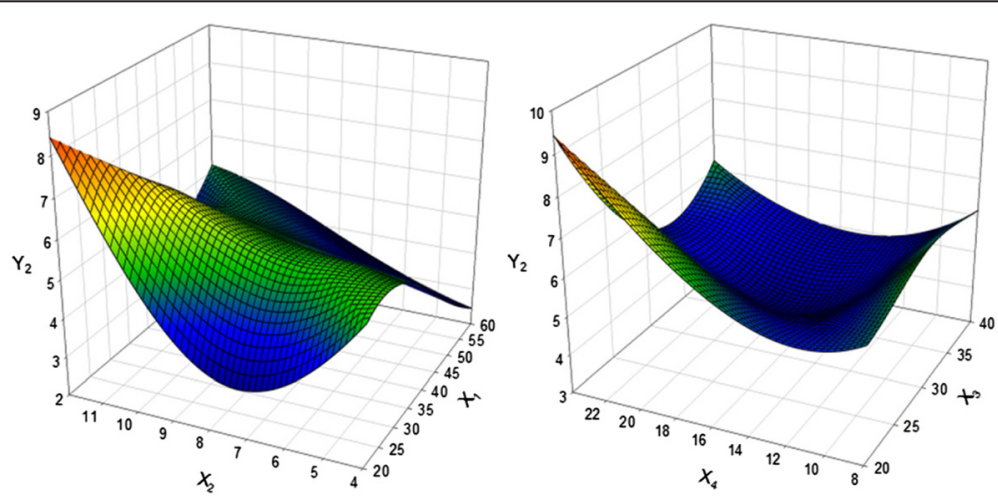

Fig. 3 Response surface plot for the effects of extraction temperature, extraction time, solvent-liquid ratio, and solvent volume on total polyphenol content of extract. $\left(X_{1}\right.$, extraction temperature $\left({ }^{\circ} \mathrm{C}\right) ; X_{2}$, extraction time (hour); $X_{3}$, Solid-liquid ratio $(\%) ; X_{4}$, solvent volume $(1: X) ; Y_{2}$, total polyphenol content (mg GAE/g)) 
Table 6 Regression analysis for regression model of physiochemical properties in extraction condition of Zea mays $L$.

\begin{tabular}{lllll}
\hline Response variables & \multicolumn{4}{l}{ F-radio $^{a}$} \\
\cline { 2 - 5 } & $X_{1}$ & $X_{2}$ & $X_{3}$ & $X_{4}$ \\
\hline Total polyphenol content (mg GAE/g) & 3.76 & 2.60 & 3.12 & 3.15 \\
Total anthocyanin content (mg C3GE/100 g) & 1.90 & 4.29 & 2.83 & 2.98 \\
Extraction yield (\%) & 8.09 & 3.34 & 0.40 & 3.44
\end{tabular}

${ }^{a} \mathrm{X}_{1}$, extraction temperature $\left({ }^{\circ} \mathrm{C}\right) ; \mathrm{X}_{2}$, extraction time (hour); $\mathrm{X}_{3}$, solid-liquid ratio $(\%) ; \mathrm{X}_{4}$, solvent volume $(1: \mathrm{X})$

activities on rat lenses and human recombinant aldose reductase [6], indicating that PCK extract exerted antidiabetic effects through protection of pancreatic $\beta$-cells, increase of insulin secretion, and AMPK activation in the liver of C57BL/KsJ db/db mice [8].

\section{Kinetics of PTP1 $\beta$ inhibition by the active compounds}

A kinetic study using $p$ NPP as a substrate at a concentration range of $0.2-1.0 \mathrm{mM}$ was performed to determine the type of inhibition compounds 7 and 11 exhibited. A kinetic analysis of PTP $1 \beta$ inhibition by compounds 7 and 11 using Lineweaver-Burk plots of 1 /velocity and $1 /$ concentration of substrate is shown in Fig. 2. When the concentration of the substrate $p$ NPP was changed, the slopes obtained with the uninhibited enzyme and the three different concentrations of each compound were found to be parallel. The results showed that the inhibition of PTP1 $\beta$ by compound 11 was mixed. However, compound 7 yielded a noncompetitive inhibition pattern against PTP1 $\beta$. In this study, polyphenol derivatives, including anthocyanins isolated from PCK, exhibited PTP1 $\beta$ inhibitory activities. These compounds may be potential lead compounds for further development as a functional food source for the prevention of diabetes.
Optimization of extraction conditions to maximize total content of polyphenol, anthocyanin content, and extraction yield

In this study, four independent parameters were used. The 27 designed experiments for optimizing the four individual parameters in the current CCD are shown in Table 3. The regression equations for response surface are listed in Table 4. The replicates (runs 23-27) at the center of the design were estimated by a pure error sum of squares. Joglekar and Ma suggested that, for a good fit of a model, $R^{2}$ should be at least 0.800 , where a value lower than 0.800 indicating the model is inappropriate for explaining the relationships between variables. RSM has been successfully used to optimize biochemical and biotechnological processes related to the food industry [18]. The main advantage of RSM is the reduced the number of experimental trials needed to evaluate multiple parameters and their interactions. Therefore, RSM is less laborious and time-consuming compared to other approaches to process optimization. The optimization of extraction parameters for TPC and TAC from PCK, will provide information and we will give a foundation for the development and utilization of PCK resources by RSM.

\section{Optimization of total polyphenol contents (TPC)}

The regression equation of changes in TPC calculated by the RSM program for various extraction conditions is shown in Table 4 with an $\mathrm{R}^{2}$ of 0.935 with less than $5 \%$ significance level recognized. TPC was at the maximum level of $7.89 \mathrm{mg} \mathrm{GAE} / \mathrm{g}$ with conditions at $29.29{ }^{\circ} \mathrm{C}\left(\mathrm{X}_{1}\right)$, $8.99 \mathrm{~h}\left(\mathrm{X}_{2}\right), 33.67 \%\left(\mathrm{X}_{3}\right)$ and 1:10.25 $\left(\mathrm{X}_{4}\right)$, respectively (Table 5). The four-dimensional response surface and contour plot shown in Fig. 3 illustrates the variation of $\mathrm{TPC}$ extraction efficiency relative to changes in $\mathrm{X}_{1}, \mathrm{X}_{2}$, $\mathrm{X}_{2}$ and $\mathrm{X}_{4}$. The response surface of TPC indicated that
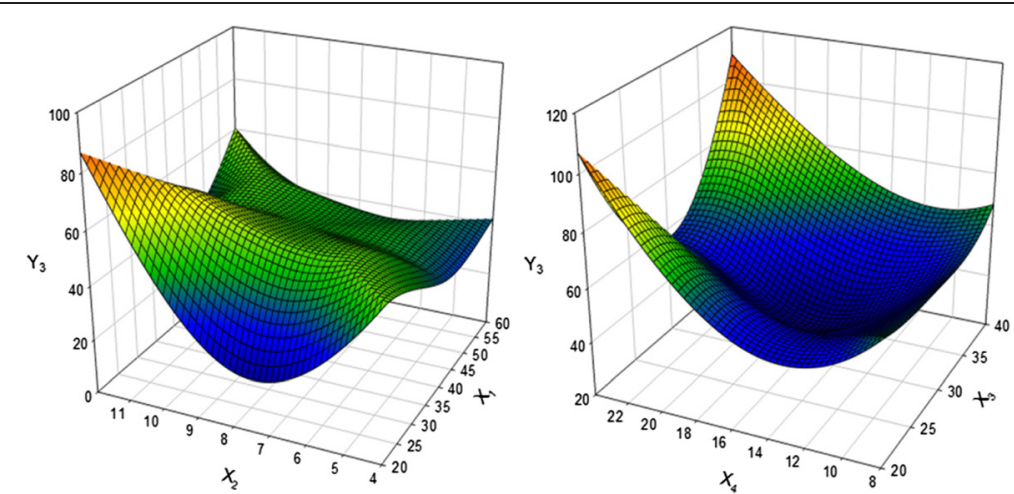

Fig. 4 Response surface plot for the effects of extraction temperature, extraction time, solvent-liquid ratio, and solvent volume on total anthocyanin content of extract. $\left(X_{1}\right.$, extraction temperature $\left({ }^{\circ} \mathrm{C}\right) ; X_{2}$, extraction time (hour); $X_{3}$, Solid-liquid ratio $(\%) ; X_{4}$, solvent volume $(1: X)$; $Y_{3}$, total anthocyanins content (mg C3GE/100 g)) 
Table 7 Predicted values of response variables at a given condition ${ }^{a}$ within the range of optimum extraction conditions

\begin{tabular}{lcc}
\hline Response variables & Predicted values & Experimental values \\
\hline $\begin{array}{l}\text { Total polyphenol content } \\
\text { (mg GAE/g) }\end{array}$ & 4.58 & 4.52 \\
$\begin{array}{l}\text { Total anthocyanin content } \\
\text { (mg C3GE/100 g) }\end{array}$ & 42.28 & 43.02 \\
Extraction yield (\%) & 5.76 & 5.87 \\
\hline
\end{tabular}

${ }^{a}$ Given conditions: $40{ }^{\circ} \mathrm{C}$ extraction temperature, $8 \mathrm{~h}$ extraction time, $33 \%$ in solid-liquid ratio, and 1:15 in solvent volume in conditions

TPC increased as $X_{1}$ and $X_{3}$ decreased and $X_{2}$ and $X_{4}$ increased (Table 6). Results showed that higher TPC (>8.3 $\mathrm{mg} \mathrm{GAE} / \mathrm{g}$ ) could be obtained when the extraction occurred at higher $\mathrm{X}_{2}(>10 \mathrm{~h})$ and $\mathrm{X}_{4}(>1: 20)$ and lower $\mathrm{X}_{1}\left(20-25{ }^{\circ} \mathrm{C}\right)$ in comparison with higher temperature and higher solid-liquid ratio. TPC should increase with longer extraction time and higher solvent volume.

\section{Optimization of total anthocyanin contents (TAC)}

In the case of TAC, the $\mathrm{X}_{2}$ and $\mathrm{X}_{4}$ were the most influential factor extraction conditions. TAC extraction from PCK under various conditions is presented in Table 3, while Fig. 4 shows the four-dimensional response surface for TAC. A significance level of less than $5 \%$ was calculated for TAC extraction from PCK with an $\mathrm{R}^{2}$ of 0.917 (Table 4). The maximum TAC predicted extraction was 82.44 mg C3GE/100 g when $\mathrm{X}_{1}, \mathrm{X}_{2}, \mathrm{X}_{2}$ and $\mathrm{X}_{4}$ volume were $45.22{ }^{\circ} \mathrm{C}, 7.85 \mathrm{~h}, 34.14 \%$, and $1: 22.97$, respectively (Table 5). In the present study, the effect of extraction time on TAC was investigated. As shown in Fig. 4, the amount of TAC extracted increased with increased of $\mathrm{X}_{2}$ up to $11 \mathrm{~h}$, resulting in a maximum of TAC $(77.94 \mathrm{mg} / \mathrm{L})$ at $10 \mathrm{~h}$. TAC was greatly affected by $\mathrm{X}_{2}$, higher $\mathrm{X}_{3}$, and higher $\mathrm{X}_{4}$, while $\mathrm{X}_{1}$ was less significant. This information was used to test the accuracy of the model's prediction of optimum response values by comparing it with the optimum levels obtained by the RSM optimization. Under the optimal conditions, the experimental extraction of TAC was $43.02 \mathrm{mg}$ C3GE/100 g; half to the predicted value in Table 7.

\section{Optimization of extraction yield (EY)}

$\mathrm{R}^{2}$ for the regression equation of EY was 0.887 with a significance of less than $5 \%$ calculated (Table 4). The predicted peak point led to the highest yield of $10.33 \%$ with corresponding independent parameters being $X_{1}$ of $58.87{ }^{\circ} \mathrm{C}, \mathrm{X}_{2}$ of $7.53 \mathrm{~h}, \mathrm{X}_{3}$ of $32.31 \%$ and $\mathrm{X}_{4}$ of $1: 17.65$ (Table 5). The four-dimensional response surface plot obtained for yields as influenced by each extraction condition is shown in Fig. 5, indicating the yield should increase with increases of $\mathrm{X}_{1}$ and $\mathrm{X}_{4}$. Overall, larger content of EY was observed with increasing $\mathrm{X}_{1}$ and $\mathrm{X}_{4}$. Table 7 shows the predicted value are close to the experimental values, with the predicted peak point led to an optimization content $5.76 \%$ of EY with the corresponding independent parameters being $\mathrm{X}_{1}\left(30-50{ }^{\circ} \mathrm{C}\right)$, $\mathrm{X}_{2}(7.5-9.0 \mathrm{~h}), \mathrm{X}_{2}(32-34 \%)$ and $\mathrm{X}_{4}(1: 10-20)$. This information was used to test the accuracy of the model's prediction of optimum response values by comparing it with the optimum levels obtained by the RSM optimization. Under the optimal conditions, the experimental EY was $5.3 \%$; close to the predicted value.

\section{Discussion}

The TPC can be influenced significantly by the solvent type, concentration, temperature, and time. In the case of high temperature, some polyphenols would be degraded and their yields would be reduced, causing a decrease in the antioxidant activity. The total phenolic compounds antioxidant activity increased with increased TPC recovery. Low temperature was ineffective in the extraction process due to diminished ability to release
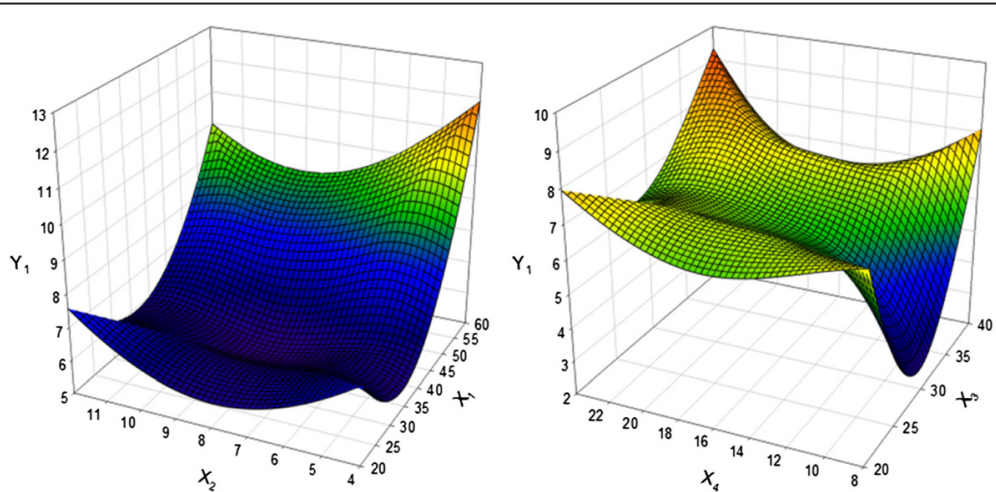

Fig. 5 Response surface plot for the effects of extraction temperature, extraction time, solvent-liquid ratio, and solvent volume on extract yield. $\left(X_{1}\right.$, extraction temperature $\left({ }^{\circ} \mathrm{C}\right) ; X_{2}$, extraction time (hour); $X_{3}$, Solid-liquid ratio $(\%) ; X_{4}$, solvent volume $(1: X) ; Y_{1}$, extract yield $\left.(\%)\right)$ 
polyphenols from fruit tissues. Also, a similar curved surface plot effect would be produced by extraction time as solvent volume in the medium and higher region. Hammi et al. reported that the yields of total phenols from Tunisian Zizyphus lotus fruits and its antioxidant activity have been significantly improved by using a $50 \%$ ethanol concentration, $63{ }^{\circ} \mathrm{C}$ temperature, and $25 \mathrm{~min}$ extraction time during conventional solvent extraction [19]. In the present study, TPC obtained at the higher time and solvent volume is similar with the previous reports for the extracts of grape cane and leaves [20,21].

Pedro et al. have reported that the yield of ATC from black rice would be influenced by the temperature and solvent ratio [15]. At longer extraction time and higher solvent volume, the extraction of ATC may reach a maxima, which may suggest the highest antioxidant activity. Moreover, Fan et al. demonstrated that the main parameter influencing ATC extraction yield from purple sweet potato was temperature [22]. The concentration gradient would be increased by raising the proportion of solvent, increasing the diffusion of solid compounds. The diffusion coefficient and the solubility of the compounds could be controlled by temperature, higher yield was obtained with increased temperature. However, anthocyanins can be damaged when temperatures are over $50{ }^{\circ} \mathrm{C}$ [23].

The temperature is an important factor for EY. Mkaouar et al. also reported the similar result [24]. The extraction efficiency critical parameter is the solubility of solutes in solvent. The viscosities of the water will decrease with the temperature increase, thereby its ability to wet the matrix and solubilize the solutes is increased. Recently, Zheng et al. reported an increased extraction rate of anthocyanin with increasing extraction temperature and static time [25]. Thus, temperature and static time have a significant effect contact time between the two phases is significantly longer, and higher extraction rates are obtained.

\section{Conclusion}

In conclusion, we have investigated whether phenolic compounds inhibit PTP1 $\beta$ activity or not, and have identified phenolic compounds from PCK that possess PTP1 $\beta$ inhibitory activity. From the twelve isolated compounds, 3 '-methoxyhirsutrin and cyanidin-3-(6"malonylglucoside) showed the potent inhibition with $\mathrm{IC}_{50}$ values of 64.04 and $54.06 \mu \mathrm{M}$ for PTP1 $\beta$, respectively. In addition, an extraction method has been developed for the extraction of total polyphenol and anthocyanin from PCK by RSM. The present results would contribute to the research about of PCK dietary supplements for diabetes treatment and optimization of extraction method.

\section{Acknowledgements}

Thanks for Jin-Kyu Kim in Biocenter, Gyeonggi Institute of Science \& Technology Promotion in Suwon supporting us in this research.

\section{Funding}

This work was supported by Korea Institute of Planning and Evaluation for Technology in Food, Agriculture, Forestry and Fisheries (IPET) through (High Value-added Food Technology Development Program), funded by Ministry of Agriculture, Food and Rural Affairs (MAFRA) (109163-3) and Basic Science Research Program through the National Research Foundation of Korea (NRF) funded by the Ministry of Education (2015R1D1A1A01059199), Hallym University Research Fund (HRF-201602-011).

\section{Availability of data and materials}

All data generated or analyzed during this study are included in this published article.

\section{Authors' contributions}

SHK and ZQW conducted the PTP1 $\beta$ inhibitory activity and analyzed the data. HSH and THK prepared the product to be tested by RSM. JYL, YHK and SSL participated in design of the study and preparation of the manuscript. All the authors read and approved the final manuscript.

\section{Competing of interests}

The authors declare that they have no competing interests.

\section{Consent for publication}

Not Applicable.

Ethics approval and consent to participate

Not Applicable.

\section{Author details}

${ }^{1}$ Department of Food Science and Nutrition, Hallym University, 1 Hallymdeahak-gil, Chuncheon 24252, Republic of Korea. ${ }^{2}$ Department of Natural Medicine, Hallym University, 1 Hallymdeahak-gil, Chuncheon 24252, Republic of Korea. ${ }^{3}$ Department of Biochemistry, School of Medicine, Hallym University, 1 Hallymdeahak-gil, Chuncheon 24252, Republic of Korea.

Received: 5 May 2016 Accepted: 17 August 2016

Published online: 26 August 2016

\section{References}

1. Tsuda T, Shiga K, Ohshima K, Kawakishi S, Osawa T. Inhibition of lipid peroxidation and active oxygen radical scavenging effect of anthocyanin pigments isolated from Phaseolus vulgaris L. Biochem Pharmacol. 1996;52:1033-9.

2. Yoshimoto M, Okuno S, Yoshinaga M, Yamakawa O, Yamaguchi M, Yamada J. Antimutagenicity of sweetpotato (Ipomoea batatas) roots. Biosci Biotech Bioch. 1999:63:537-41.

3. Koide T, Hashimoto Y, Kamei H, Kojima T, Hasegawa M, Terabe K. Antitumor effect of anthocyanin fractions extracted from red soybeans and red beans in vitro and in vivo. Cancer Biother Radiopharm. 1997;12:277-80.

4. Yang Z, Chen Z, Yuan S, Zhai W, Piao X, Piao X. Extraction and identification of anthocyanin from purple corn (Zea mays L.). Int J Food Sci Tech. 2009:44:2485-92.

5. Pascual-Teresa SD, Santos-Buelga C, Rivas-Gonzalo JC. LC-MS analysis of anthocyanins from purple corn cob. J Sci Food Agr. 2002;82:1003-6.

6. Kim TH, Kim JK, Kang YH, Lee JY, Kang IJ, Lim SS. Aldose reductase inhibitory activity of compounds from Zea mays L. BioMed Res Int. 2013;2013:8-15.

7. Li Z, Lim SS, Lee JY, Kim JK, Kang SW, Kim JL, Kang YH. Purple corn anthocyanins dampened high-glucose-induced mesangial fibrosis and inflammation: possible renoprotective role in diabetic nephropathy. J Nutr Biochem. 2012;23:320-31.

8. Huang B, Wang ZQ, Park JH, Ryu OH, Choi MK, Lee JY, Kang YH, Lim SS. Anti-diabetic effect of purple corn extract on C57BL/KsJ db/db mice. Nutr Rer Pract. 2015;9:22-9.

9. Schultz LD, Schweitzer PA, Rajan TV, Yi T, Ihle JN, Matthews RJ, Thomas ML, Beier DR. Mutations at the murine motheaten locus are within the hematopoietic cell protein tyrosine Phosphatase (Hcph) gene. Cell. 1993;73:1445-54.

10. Bialy L, Waldmann $\mathrm{H}$. Inhibitors of protein tyrosine phosphatase: Nextgeneration drugs? Angew Chem Int Edit. 2005;44:3814-39.

11. Asante-Appiah E, Kennedy BP. Protein tyrosine phosphatase: the quest for negative regulators of insulin action. Am J Physiol. 2003;284:663-70. 
12. Lee YS, Kang IJ, Won MH, Kim JK, Lim SS. Inhibition of protein tyrosine phosphatase 1 beta by hispidin derivatives isolated from the fruiting body of Phellinus linteus. Nat Prod Commun. 2010;5:1927-30.

13. Bezerra MA, Santelli RE, Oliveira EP, Villar LS, Escaleira LA. Response surface methodology (RSM) as a tool for optimization in analytical chemistry. Talanta. 2008;284:965-77.

14. Ghafoor K, Choi YH. Optimization of ultrasound assisted extraction of phenolic compounds and antioxidants from grape peel through response surface methodology. J Korean Soc Appl Bl. 2009;52:295-300.

15. Pedro AC, Granato D, Rosso ND. Extraction of anthocyanins and polyphenols from black rice (Oryza sativa L.) by modeling and assessing their reversibility and stability. Food Chem. 2016;191:12-20.

16. Li HM, Hwang SH, Kang BG, Hong JS, Lim SS. Inhibitory effects of Colocasia esculenta (L.) Schott constituents on aldose reductase. Molecules. 2014:19:13212-24

17. Rodrigues S, Fabiano AN, Fernandes A, Brito ESD, Sousa AD, Narain N. Ultrasound extraction of phenolics and anthocyanins from jabuticaba peel. Ind Crop Prod. 2015;69:400-7.

18. Joglekar AM, May AT. Product excellence through design of experiment. Cereal Food World. 1987;32:857-68.

19. Hammi KM, Jdey A, Abdelly C, Majdoub H, Ksouri R. Optimization of ultrasound-assisted extraction of antioxidant compounds from Tunisian Zizyphus lotus fruits using response surface methodology. Food Chem. 2015;184:80-9.

20. Karacabey E, Mazza G. Optimisation of antioxidant activity of grape cane extracts using response surface methodology. Food Chem. 2010;119:343-8.

21. Prasad K, Nath N. Mathematical modeling and optimisation of sugarcane juice level in grape beverage using response surface methodology (RSM). J Dairy Foods Home Sci. 2011;30:278-84.

22. Fan G, Han Y, Gu Z, Chen D. Optimizing conditions for anthocyanins extraction from purple sweet potato using response surface methodology (RSM). LWT-Food Sci Tech. 2008;41:155-60.

23. Cacace JE, Mazz G. Optimization of extraction of anthocyanins from black currants with aqueous ethanol. J Food Sci. 2003;68:240-8.

24. Mkaouar S, Bahloul N, Gelicus A, Allaf K, Kechaou N. Instant controlled pressure drop texturing for intensifying ethanol solvent extraction of olive (Olea europaea) leaf polyphenols. Sep Purif Technol. 2016:145:12-20.

25. Zheng X, Xu X, Liu C, Sun Y, Lin Z, Liu H. Extraction characteristics and optimal parameters of anthocyanin from blueberry powder under microwave-assisted extraction conditions. Sep Purif Technol. 2013;104:17-25.

\section{Submit your next manuscript to BioMed Central and we will help you at every step:}

- We accept pre-submission inquiries

- Our selector tool helps you to find the most relevant journal

- We provide round the clock customer support

- Convenient online submission

- Thorough peer review

- Inclusion in PubMed and all major indexing services

- Maximum visibility for your research

Submit your manuscript at www.biomedcentral.com/submit
Biomed Central 